\title{
BETTER HEALING PROCESS BY USING PROTOCOLS IN ICUS IN PLOVDIV, BULGARIA
}

\author{
Valentina Lalova, Gergana Petrova, Elena Merdzhanova \\ Department of Nursing, Faculty of Public Health, Medical University - Plovdiv, \\ Bulgaria.
}

\section{SUMMARY}

Purpose: The purpose of this study was to compare perceived utility by the ease of use, patient safety, drug therapy and compliance of protocols between nurses and physicians.

Materials and Methods: The survey covered 178 medical specialists. Have been used documentary and survey methods. Data has been analyzed by using the software package SPSS v. 21.0 and graphics were prepared by using the program Microsoft Excel '13.

Results: Almost half of respondents, $41.01 \%$ believe that protocols can contribute to reducing mortality and morbidity in $\mathrm{ICU}^{\mathrm{s}}$ due to early recognition of patient worsening $\mathrm{p}=0.000\left(\chi^{2}=24.48\right.$, $\mathrm{df}=4)$. The remaining part $46.63 \%$ totally agree with this, the others $4.49 \%$ cannot predict, and $7.87 \%$ rather believe that this will not affect the mentioned indicators. Protocols can avoid a sudden change in basic vital functions, such as breathing rate, blood pressure, consciousness level, etc. and these changes should not be missed $\mathrm{p}=0.010\left(\chi^{2}=13.35, \mathrm{df}=4\right)$. More than $51.69 \%$ of the practitioners consider that and other $40.45 \%$ fully support this claim. Around $6.18 \%$ rather believe that this cannot be influenced, $1.69 \%$ cannot judge. A high percentage of 97 $(54.50 \% \pm 3.73)$ specialists, who are working in $\mathrm{ICU}^{\mathrm{s}}$ believe that the use of protocols contributes to the prevention of adverse drug reactions $\mathrm{p}=0.000$ $\left(\chi^{2}=23.41, \mathrm{df}=4\right)$.

Conclusions: Overcoming the perceived barriers of protocol use within $\mathrm{ICU}^{\mathrm{s}}$ requires personnel for development and physician support. A better protocol review process is necessary to assure optimal content, desired outcomes, and consistency with safe medication practices guidelines.

Keywords: protocols, intensive cares, $\mathrm{ICU}^{\mathrm{s}}$, nurses,

\section{INTRODUCTION:}

The significant technological advances have allowed intensive care units to be monitored through the centralized work of a multidisciplinary team of specialists $[1,2,3]$. Intensive units have been provided cares at different levels of support for intensive patients. The development of protocols for the work of nurses, aims to facilitate their dayto-day activities, improving the outcomes and safety of patients and all staff $[4,5,6,7]$. The performance of nurses, as an integral part of multidisciplinary teams in $\mathrm{ICU}^{\mathrm{s}}$, is evidence that mortality and morbidity can be prevented, thanks to the early recognition of patient " deterioration and rapid resuscitation [8].

For the first time in Bulgaria, an internationally validated Hospital Survey on Patient Safety Culture (HSOPSC), which had been developed by AHRQ, US and had been translated in more than 30 countries, was attached to the survey. [9].

\section{AIM:}

The purpose of this study was to compare perceived utility by the ease of use, patient safety, drug therapy and compliance of protocols between nurses and physicians. To understand the effectiveness and benefits derived from the organisation of the working process.

\section{MATERIALS AND METHODS:}

It is important to assess the activities carried out by the nurses, who do not have experience working in ICU ${ }^{\mathrm{s}}$. Have been used documentary and survey methods, data has been analysed by using the software package SPSS v. 21.0 and graphics have been prepared by using the program Microsoft Excel' 13. 


\section{RESULTS:}

Fig. 1. The distribution of respondents to the claim that the use of clinical protocols can contribute to reducing mortality and morbidity in ICUs due to early recognition of patient worsening

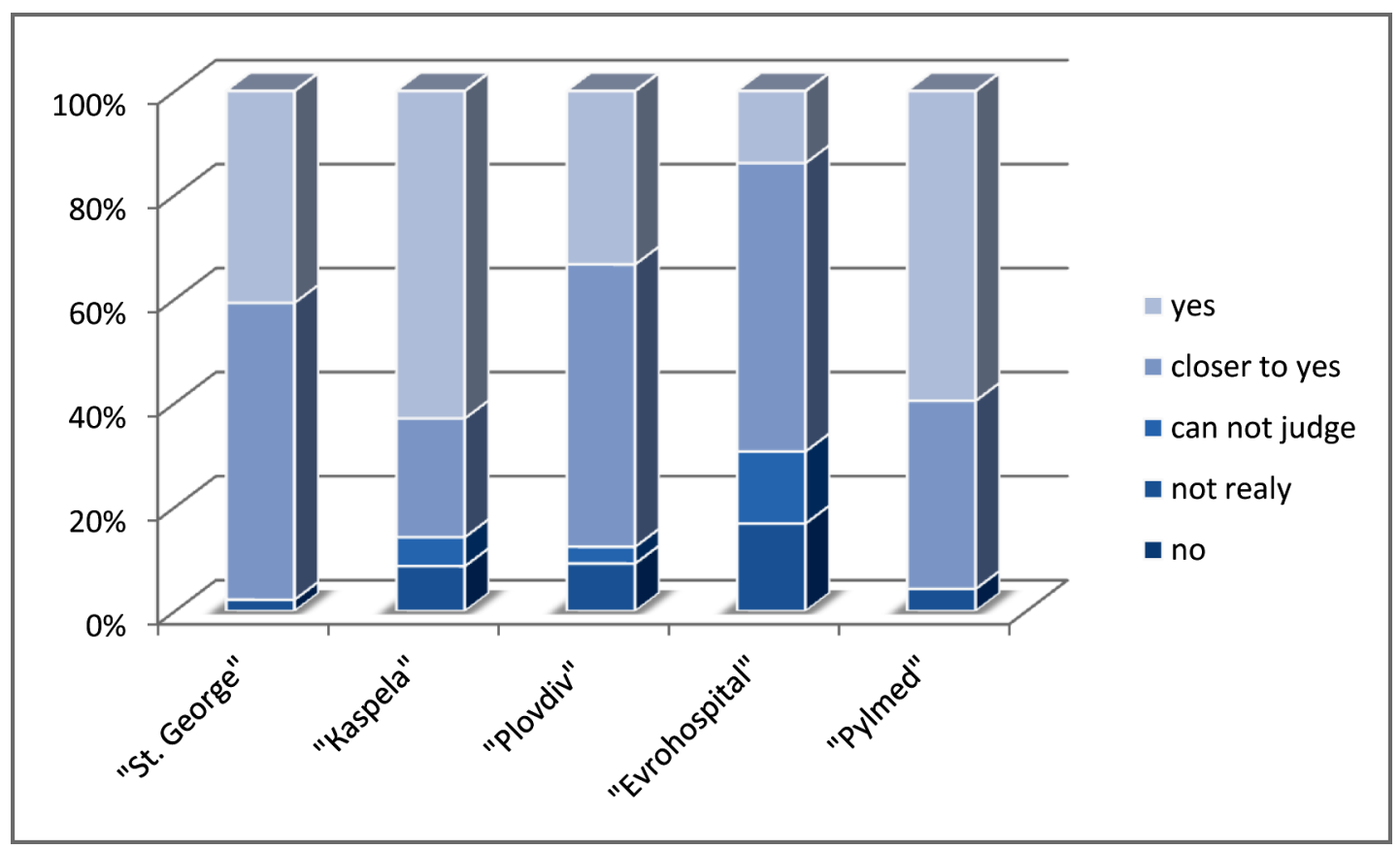

Almost half of respondents, $41.01 \%$ believe that protocols can contribute to reducing mortality and morbidity in $\mathrm{ICU}^{\mathrm{s}}$ due to early recognition of patient worsening $\mathrm{p}=0.000\left(\chi^{2}=24.48, \mathrm{df}=4\right)$. The remaining part $46.63 \%$ totally agree with this, the others $4.49 \%$ cannot predict, and $7.87 \%$ rather believe that this will not affect the mentioned indicators.

Fig. 2. The distribution of respondents to the claim that the use of clinical protocols can avoid a sudden change in basic vital functions, such as breathing rate, blood pressure, consciousness level, etc. and these changes should not be missed

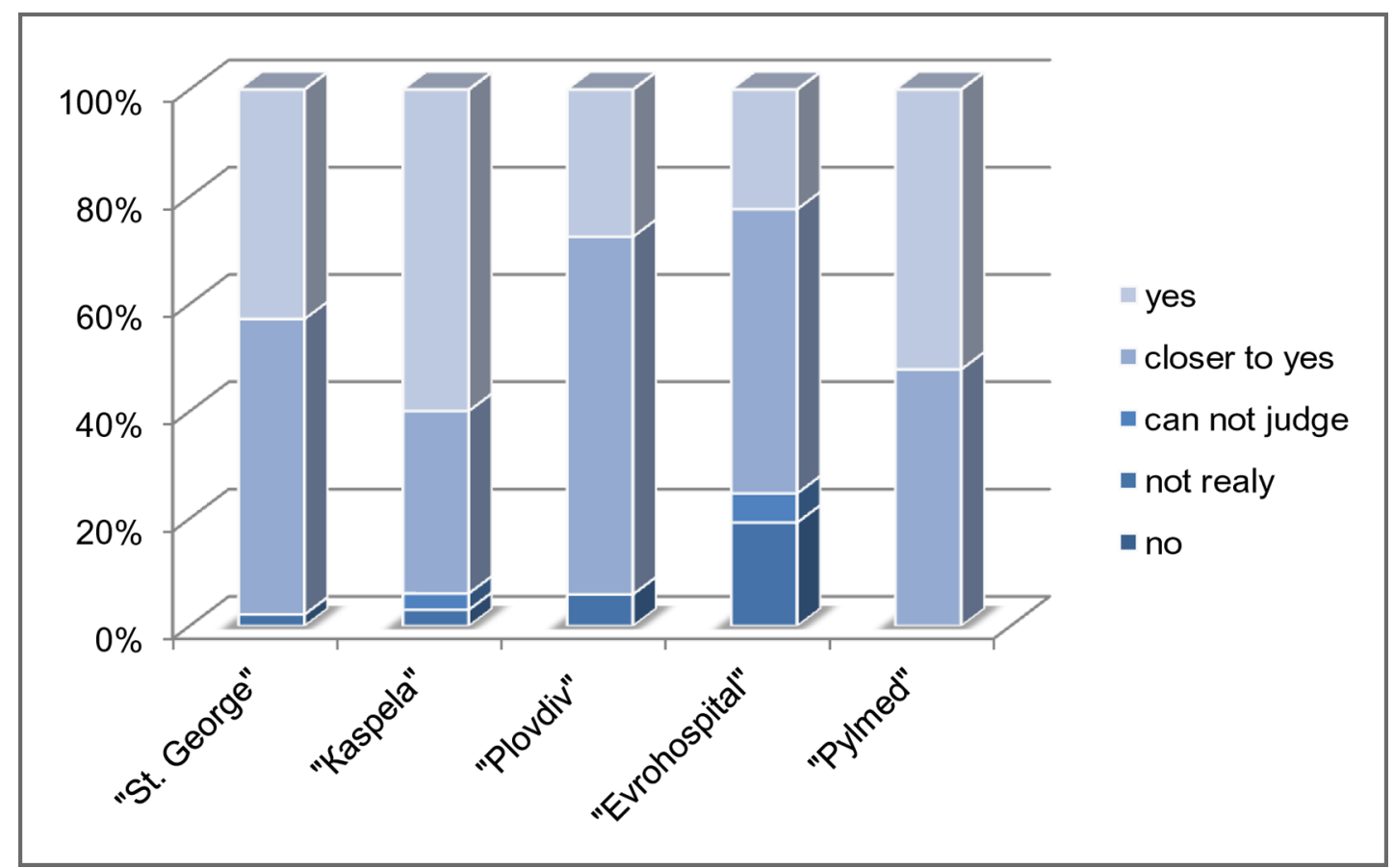


Protocols can avoid a sudden change in basic vital functions, such as breathing rate, blood pressure, consciousness level, etc. and these changes should not be missed $\mathrm{p}=0.010 \quad\left(\chi^{2}=13.35, \mathrm{df}=4\right)$. More than $51.69 \%$ of the practitioners consider that and other $40.45 \%$ fully support this claim. Around $6.18 \%$ rather believe that this cannot be influenced, $1.69 \%$ cannot judge.

Fig. 3. Distribution of respondents to the claim that the use of protocols contributes to the prevention of adverse drug reactions.

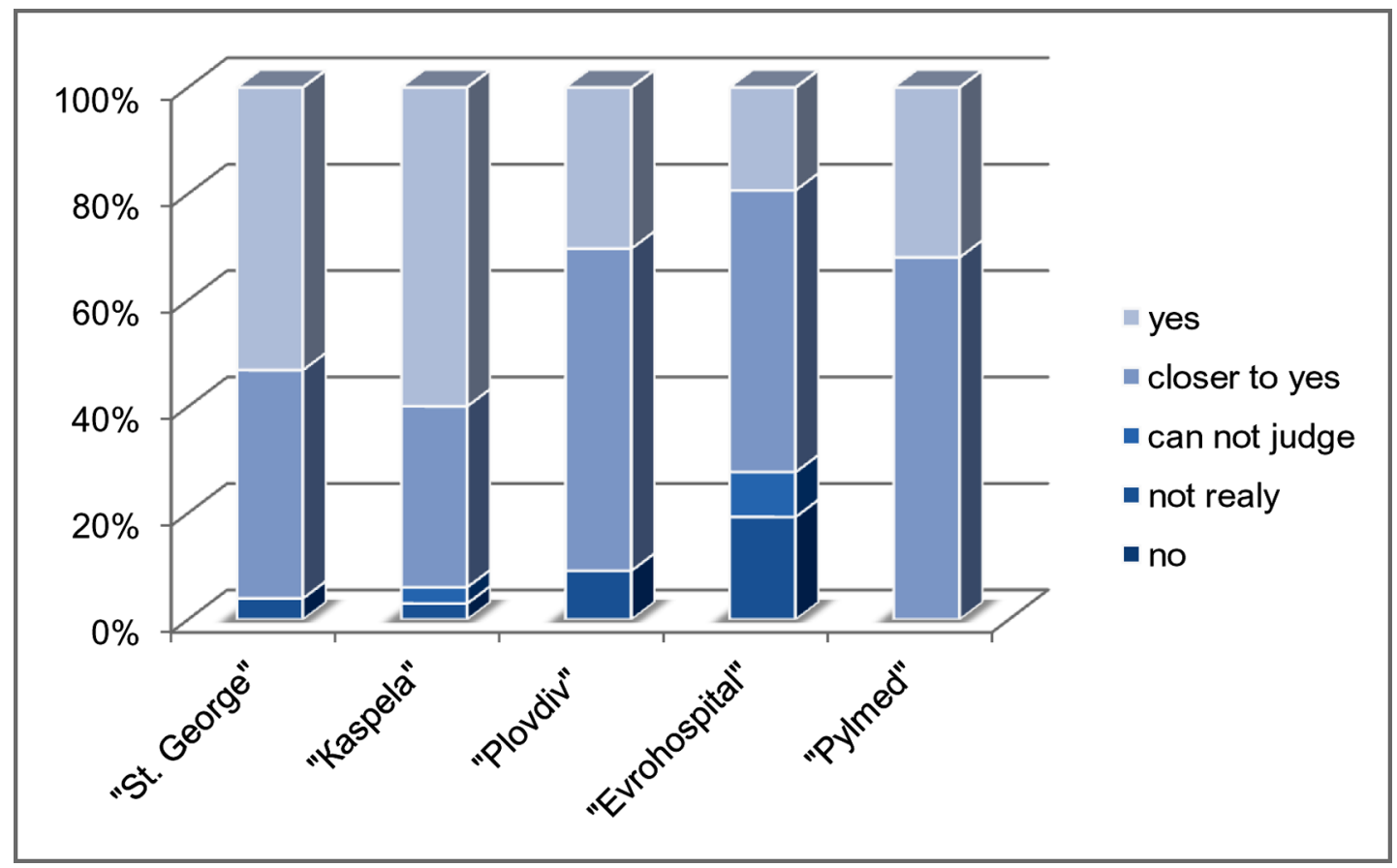

A high percentage of $97(54.50 \% \pm 3.73)$ specialists, who are working in $\mathrm{ICU}^{\mathrm{s}}$ believe that the use of protocols contributes to the prevention of adverse drug reactions $\mathrm{p}=0.000\left(\chi^{2}=23.41, \mathrm{df}=4\right)$.

\section{DISCUSSION:}

After this survey, we can say that usage of protocols in $\mathrm{ICU}^{\mathrm{s}}$, requires constantly evolving staff, which has to be supported by the physician. The better healing process is accomplished by optimizing the content, using new technologies and techniques, also periodically evaluation of the desired results. Protocol use has substantially increased over the past decade. Patient outcomes associated with protocol use have typically demonstrated positive results $[10,11]$. This is the first study to study the views of interdisciplinary, critical care clinicians in the development, implementation, assessment, and perception of the utility of protocols. This information will be useful for institutions developing such protocols and for those institutions encouraging compliance with existing protocols. Both professions indicated that the most important advantage of protocols was improved patient outcomes. Protocol implementation has been demonstrated in the literature to improve mortality and morbidity outcomes. [10, 11, 12]. Sedation protocols have been shown to decrease the duration of mechanical ventilation and length of stay in hospital [10]. Protocols managing transfusion management, sepsis resuscitation, and ventilatorassociated pneumonia have also shown improved outcomes $[10,13]$. Drug protocols were identified as the most frequently used protocol to improve patient outcomes. This is supported by a recent analysis showing that incorporating "sepsis bundles" improved antibiotic use among the heterogeneous studies [13].

\section{CONCLUSION:}

Improved healing can be accomplished by optimizing the content and evaluation of the desired results, in association with good doctor practices. We should have developed a more flexible framework, which has been accepted by standard, which will improve the quality of cares. Educational programs must be improved, and their effect should be studied. There are concerns that the lack of nurses in $\mathrm{ICU}^{\mathrm{s}}$ in Bulgaria has been seriously increased. 
REFERENCES:

1. Franklin C, Mathew J. Developing strategies to prevent in hospital cardiac arrest: analysing responses of physicians and nurses in the hours before the event. Critical Care Medicine. 1994; 22:244-7

2. Hillman KM, Bristow PJ, Chey T, Daffurn K, Jacques T, Norman SL, et al. Duration of life-threatening antecedents prior to intensive care admission. Intensive Care Med. 2002 Nov; 28(11): 1629-34. [PubMed] [Crossref]

3. Smith AF, Wood J.. Can some inhospital cardio-respiratory arrests be prevented? A prospective survey. Resuscitation. 1998 Jun; 37(3):133-7.

4. Goldhill DR. Medical Emergency Teams. Care of the Critically Ill. 2000; 16:209-12.

5. Lalova V, Petrova G, Merdzhanova E. Assessment of various aspects of using protocols in intensive care units in Plovdiv, Bulgaria. Medical Sci- ence Pulse. 2019; 13(2): 3-5. [Crossref]

6. Lalova V, Petrova G, Kulina H, Merdjanova E. Factors for limited application of identical protocols in intensive care units. Trakia Journal of Sciences. 2018; 16(Suppl. 1):215-219. [Crossref]

7. McGaughey J, Alderdice F, Fowler R, Kapila A, Mayhew A, Moutray M. Outreach and Early Warning Systems (EWS) for the Prevention of Intensive Care Admission and Death of Critically Ill Adult Patients on General Hospital Wards. Cochrane Database Syst Rev. 2007 Jul 18;(3): CD005529. [PubMed] [Crossref].

8. Lee A, Bishop G, Hillman KM, Daffurn K. The Medical Emergency Team. Anaesth Intensive Care. 1995 Apr;23(2):183-6

9. Stoyanova R, Dimova R, Tarnovska M, Boeva T. Linguistic validation and cultural adaptation of Bul- garian version of hospital survey on patient safety culture (HSOPSC). Open Access Maced J Med Sci. 2018 May 18;6(5):925-930. [PubMed] [Crossref]

10. McQuillan P, Pilkington S, Allan A, Taylor B, Short A, Morgan G, et al. Confidential inquiry into quality of care before admission to intensive care. BMJ. 1998 Jun; 316(7148): 18538. [PubMed] [Crossref]

11. Morgan R, Williams F, Wright M. An early warning scoring system for detecting developing critical illness. Clinical Intensive Care. 1999;(8):100.

12. Munro CL. The "Lady With the Lamp" Illuminates Critical Care Today. Am J Crit Care. 2010 Jul;19(4):315-7. [PubMed] [Crossref]

13. Mushin WW, Lunn JN. The anaesthetist and intensive care. $\mathrm{Br}$ Med J. 1969 Jun 14;2(5658):683-4. [PubMed] [Crossref]

Please cite this article as: Lalova V, Petrova G, Merdzhanova E. Better healing process by using protocols in ICUs in Plovdiv, Bulgaria. J of IMAB. 2020 Apr-Jun;26(2):3098-3101. DOI: https://doi.org/10.5272/jimab.2020262.3098

Received: 14/05/2019; Published online: 28/04/2020

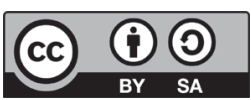

Address for correspondence:

Assist. Prof. Valentina Lalova, PhD

Department of Nursing, Faculty of Public Health, Medical University - Plovdiv 15A, Vasil Aprilov blvd., Plovdiv 4002, Bulgaria,

E-mail: suzy_lalova@yahoo.com, 